\title{
MICHELE HAMPSON
}

\section{It just took a blank sheet of paper: changing the job plan of an adult psychiatrist}

Many good ideas seemingly come out of the blue - in my case, dreaming of early retirement. If work felt like a painful sprint, at least it would be short-lived. I considered the impact of a stressed, adult psychiatrist on recruitment, for medical students and junior trainees spend the majority of their training with such consultants. Early retirement can increase the workload of the remaining psychiatrists, given the existing unfilled posts, which can create a domino effect. Previously, the idea of jogging along had felt self-indulgent. Now, it seemed as essential for the profession as for myself.

The pressures on psychiatrists working in community mental health teams are well understood. They are unable to ring-fence their services to the extent of their specialist colleagues, routine work is frequently interrupted by crises, bed occupancy is rising despite reduced length of stay, Mental Health Act 1983 work is increasing and caseloads are high. There are additional administrative demands such as the Care Programme Approach (CPA). An increasingly articulate user and carer movement is understandably demanding more time to discuss their care. The psychiatrist is increasingly concerned about risk management, and often feels like the repository of such anxiety for the team. The chance to meet formally or informally with colleagues has diminished. The demise of the doctors' mess, where one could get a few minutes' advice and support over a lunch break (what is that now?) have gone, due not only to time constraints, but also to consultants being dispersed into community teams.

My training and job plan belonged to a former doctor-based service model. Working systematically could produce greater gains. In reality, contact with general practitioners (GPs) was crammed between patients. The community team and day unit staff were clamouring for fixed time slots between weekly meetings to discuss pressing concerns. The routine work pressures meant that the potentially more complex crisis work was sometimes initially managed by less experienced staff. It was easier to accept GP referrals than to spend time discussing what further options the GPs themselves could implement. It takes time to control the work coming into the team and to avoid unnecessary hospitalisation, and that I did not have.
I resolved to become a 'consultant' again, that is one who is actually consulted. This required increased availability for staff of all disciplines, both in primary and secondary care, to provide advice, support, training, joint-working and supervision, to liaise with other agencies in the community and to provide direct clinical input into the care of the most complex cases. I wanted time to contribute to service developments and to seek not only to train medical students, but to inspire them to enter our profession. To achieve this, time was needed for reflection, training and meetings with colleagues. As I alone was responsible for the changes, I resolved not to place any burden on my colleague through cross-over arrangements. I wanted, if possible, to meet the expectation of service users and carers, that doctors will respond rapidly to calls for advice as well as crises. Could a realistic job plan be devised to take all these factors into account?

\section{Devising the job plan}

Producing a new job plan simply required a blank piece of paper and a prioritisation of the various activities for inclusion in the timetable. I chose to ensure that I would be in my office from 11-12 a.m. as this is a good time to communicate with GPs. They were advised by letter and through a training event of my availability to discuss patients, including offering advice for those not under my care. Similarly, I ensured that I was available for the community team and, with many of them working parttime, two slots were needed. They were told that they could also contact me between 11-12 a.m., if I was not on the phone to a GP. The post-discharge team, based at the hospital, had a separate review time. Next the allocation meeting, trainee supervision, case conference and journal club were included. A session for service development, research and audit, hitherto a luxury undertaken out-of-hours, was put into the timetable, as this was a pre-requisite for avoidance of burnout. Leaving the direct clinical contact till last, it became clear that there was no additional time available to the ward and that clinic time would have to be reduced by $40 \%$. The solution to the latter problem was partly to develop a telephone service 
for patients. I would contact them to review response to medication or a behavioural programme and they could contact me by phone between 11:15 and 11:45 for advice if problems arose. 'Routine' appointments ceased; each out-patient appointment had to have a specific purpose. I spent more time in discussion with the Clinical Assistant and ensured that he too used his time as efficiently as possible. More time was spent in joint reviews, with the community team and day unit staff.

\begin{tabular}{|c|c|c|}
\hline Activity (mins) & $\begin{array}{l}\text { Pre- } \\
\text { intervention }\end{array}$ & $\begin{array}{l}\text { Post- } \\
\text { intervention }\end{array}$ \\
\hline \multirow[t]{2}{*}{ Time worked/week } & 45 hours & 44 hours \\
\hline & 40 mins* & 42 mins* \\
\hline Lunch break & 10 & 32 \\
\hline CPD & 181 & $222 *$ \\
\hline New patient contacts - routine & 129 & 77 \\
\hline Out-patient follow-ups & 547 & 415 \\
\hline Emergency assessments & 70 & 96 \\
\hline Home visits & 44 & 43 \\
\hline $\begin{array}{l}\text { Phone contact patients and } \\
\text { carers }\end{array}$ & 10 & $47^{* *}$ \\
\hline Phone contact primary care & 19 & 32 \\
\hline Phone contact other agencies & 22 & 8 \\
\hline $\begin{array}{l}\text { Liaison with team including } \\
\text { allocation meeting }\end{array}$ & 115 & 132 \\
\hline $\begin{array}{l}\text { Ward contact including phone } \\
\text { calls }\end{array}$ & 327 & 297 \\
\hline $\begin{array}{l}\text { Teaching and supervision of } \\
\text { trainees }\end{array}$ & 164 & 130 \\
\hline Administration & 538 & 454 \\
\hline Management/committees & 142 & 125 \\
\hline Travel & 112 & 104 \\
\hline Special leave & 0 & 78 \\
\hline Annual leave & 310 & 390 \\
\hline
\end{tabular}

CPD, continuing professional development

*This assumes that annual, study and special leave days are 8 hours long $P<0.05, * * P<0.005$
The change from the old to the new plan was evaluated using daily activity monitoring for 3 months before and after implementation. The first sample covered 42 days and the second the following 80 days.

\section{The effect of the change: the hard facts}

The medical director and chief executive were supportive of the job plan changes. The breakdown of activity is as shown in Table 1, which shows adherence to the plan. I was more likely to attend the weekly lunch break with colleagues before the journal club, but otherwise lunch breaks were rare. Disappointingly, it was still unusual for the GPs to initiate contact, though this had increased significantly.

\section{The impact of the revised job plan: impressions}

The new job plan (Table 2) reduced stress to such an extent that I had assumed there to be a significant reduction in the hours of work, which was not the case. This comes from having time for more crisis work and discussion with the community team. I think that having time to spend with individual team members, rather than seeing the patient oneself, allows for the development of their skills in a supportive environment. They have commented favourably on the changes. Having time to reflect on my own clinical practice, I too was more likely to consult and develop my personal clinical skills. Being less tired, I think I have become more creative and so effective, enjoying the clinics rather than surviving them. I may not have reduced my hours of work, but I have been able to take on new leadership roles in the Trust.

The changes described are similar to the new consultant role described by Kennedy and Griffiths (2001). General practitioners rarely initiated contact, but spontaneously said how much they valued the change a year on. On questioning them further, they said that they

Table 2. Revised job plan

\begin{tabular}{|c|c|c|c|c|}
\hline Monday & Tuesday & Wednesday & Thursday & Friday \\
\hline $\begin{array}{l}\text { 9:11 Discuss } \\
\text { in-patients }\end{array}$ & $\begin{array}{l}\text { 9-10:30 Allocation } \\
\text { meeting 10:30-11:00 } \\
\text { Managers meeting. } \\
\text { Monthly team management } \\
\text { meeting }\end{array}$ & $\begin{array}{l}\text { 9-11 Study, administration, } \\
\text { committee meetings and/ } \\
\text { or crisis work }\end{array}$ & $\begin{array}{l}\text { 9-10:30 Out-patient clinic } \\
\text { at Health Centre }\end{array}$ & $\begin{array}{l}\text { 9-11 Clinic at team } \\
\text { base }\end{array}$ \\
\hline $\begin{array}{l}\text { 12:10-13:50 Case } \\
\text { conference } \\
\text { 14:00-17:00 Clinic } \\
\text { at team base }\end{array}$ & $\begin{array}{l}\text { 12:00-12:30 Lunch } \\
\text { 12:30-13:30 Supervision } \\
\text { trainee } \\
\text { 13:30-17:00 Flexible - in- } \\
\text { cluding crisis management, } \\
\text { ward visits and/or adminis- } \\
\text { tration }\end{array}$ & $\begin{array}{l}\text { 12:00-12:30 Lunch } \\
\text { 12:30-17:00 Study, crisis } \\
\text { work and/or administration }\end{array}$ & $\begin{array}{l}\text { 12:00-12:15 Lunch } \\
\text { 12:15-13:15 Supervision } \\
\text { trainee } \\
\text { 13:30-14:00 Post } \\
\text { Discharge Team Case } \\
\text { Review } \\
\text { 14:00-17:00 Ward review }\end{array}$ & $\begin{array}{l}\text { 12:00-12:30 Lunch } \\
\text { 12:30-13:30 } \\
\text { Community team } \\
\text { time } \\
\text { 13:30-17:00 } \\
\text { Administration or } \\
\text { crisis work }\end{array}$ \\
\hline
\end{tabular}

GP, general practitioner 
were pleased that I contacted them more frequently, as they used the opportunity to discuss other patients at the same time. There is considerable evidence of the difficulty in finding constructive ways of improving liaison with primary care (Bower et al, 2002). Given that the GPs do not use the time slot available to them, there is a temptation to let the clinics expand rather than use this time to be available to staff and patients. Old habits die hard. The monitoring exercise was probably useful in ensuring a fidelity to the model and it may need to be repeated. The next task is to reduce the average week to 48 hours and to actually take lunch breaks.

Telephone contact has been shown to be effective in the management of depression (Dietrich, 2000), and, as calls can be fitted into spare moments, they were very time-efficient. Patients said that knowledge of my availability left them feeling more secure, even though, like the GPs, they rarely phoned me. If problems had arisen, they could be seen quickly outside of fixed clinic times.

There is a growing emphasis on job planning, a key element of the consultant contract that was rejected in England. It will remain important not only as a way of monitoring and changing service delivery, but also in the context of 'Improving Working Lives' initiatives. Colgan (2002) suggested that the College should 'devise realistic but ambitious model job plans that would sustain consultants in difficult working environments'. I share a sector of 92000 with a consultant colleague in a sector that is deprived (MINI score of 103.6). I hope that this article can encourage others to go down the same road. The changes are best seen as work in progress. In particular, the use of telephone contact could be developed further. I can now envisage a longer working life than would have been the case 2 years ago - the goal of this exercise.

\section{Acknowledgement}

I am grateful to Dr Peter Kennedy for the advice that he gave me.

\section{References}

BOWER, P. \& SIBBALD, B. (2002) On site DIETRICH, A. J. (2000) The telephone as mental health workers in primary care: effects on professional practice (Cochrane Review). InThe Cochrane a new weapon in the battle against depression. Effective Clinical Practice 3,191-193. Library, Issue 1. Oxford: Update Software.

KENNEDY, P. \& GRIFFITHS, H. (2001) General psychiatrists discovering new COLGAN, S. (2001) Who wants to be a roles for a new era. British Journal of general psychiatrist? Psychiatric Psychiatry, 179, 283-285. Bulletin, 25, 3-4

M. Hampson Consultant Psychiatrist, North Nottingham \& Hucknall Community Mental HealthTeam, Rosebery House, Waterford Street, Old Basford, Nottingham NG6 0DH. Email: michele.hampson@nottshc.nhs.uk 